\title{
Consumo, digestibilidade de nutrientes e balanço de nitrogênio da silagem de capim-elefante com adição de pedúnculo de caju desidratado
}

\author{
Intake, nutrients digestibility and nitrogen balance of elephant grass silages added different \\ levels of dehydrated cashew stalk
}

\begin{abstract}
Margareth Maria Teles ${ }^{I}$ José Neuman Miranda NeivaII Rossana Herculano Clementino ${ }^{\text {III }}$ Aníbal Coutinho do Rêgo ${ }^{\mathrm{IV}}$ Magno José Duarte Cândido ${ }^{\mathrm{V}}$ João Restle $^{\mathrm{VI}}$
\end{abstract}

RESUMO

A presente pesquisa foi realizada com o objetivo de avaliar o valor nutritivo de silagens de capim-elefante contendo níveis crescentes de pedúnculo de caju desidratado (PCD). Foram utilizados 20 ovinos machos e não castrados, seguindo o delineamento experimental inteiramente casualizado, com cinco tratamentos (níveis de adição de 0; 4; 8; 12 e 16\%) e quatro repetições. Foram avaliados os consumos e a digestibilidades da matéria seca (MS), da matéria orgânica $(M O)$, da proteína bruta (PB), da fibra em detergente neutro (FDN), da fibra em detergente ácido (FDA), do extrato etéreo (EE), dos carboidratos totais (CHT), dos carboidratos não fibrosos (CNF), além do valor de nutrientes digestíveis totais (NDT) e do balanço de nitrogênio (BN) das silagens. A adição de PCD não influenciou os consumos de MS, MO, FDN, FDA, CHT e NDT expresso em \% PV e $\mathrm{kg}^{-1} \mathrm{PV}^{0,75} \mathrm{e}$ as digestibilidades da $M O, P B, F D N$, FDA e CHT das silagens. No entanto, a adição do PCD promoveu aumento nos consumos de $P B, E E$ e CNF (\% PV e g $\mathrm{kg}^{-1} \mathrm{PV}^{0,75}$ ), nas digestibilidades do EE e dos CNF e no valor de NDT e balanço de nitrogênio. Por outro lado, a inclusão de PCD na ensilagem do capim-elefante promoveu efeito linear decrescente na digestibilidade da FDA das silagens. Conclui-se que as silagens com adição de PCD podem ser utilizadas como volumoso para ruminantes em razão das melhorias nos consumos de PB, EE e CNF e nas digestibilidades do EE e dos CNF, além do valor de NDT e BN das silagens, recomendando-se a adição de até $16 \%$ na matéria natural.

Palavras-chave: Anacardium occidentale L., ensilagem, ovinos, valor nutritivo.

\begin{abstract}
The nutritive value of elephant grass silages, with increasing levels of dehydrated cashew stalk (DCS) was evaluated. Five addition levels were studied $(0 ; 4 ; 8 ; 12$ and 16\%), using 20 rams in a completely randomized design with five treatments (addition levels) and four replicates (animals). Intake and digestibility of dry matter (DM), organic matter $(O M)$, crude protein $(C P)$, neutral detergent fiber (NDF), acid detergent fiber ( $A D F)$, ether extract (EE), total carbohydrates (TC) and non-fibrous carbohydrates (NFC) were determined, as well as total digestible nutrients (TDN) and silages nitrogen balance (NB). DCS did not affect intakes of DM, OM, NDF, $A D F, T C$ and TDN, neither digestibility of $O M, C B, N D F, A D F$ and TC silages. Otherwise, the addition of DCS increased intakes of CP, EE and NFC and digestibility of EE, NFC, as well as TDN values and nitrogen balance. Inclusion of DCS showed linear decreasing digestibility of ADF. It is concluded that addition of DCS to silages of elephant grass up to $16 \%$ on a natural basis can be used as a forage source for ruminants.
\end{abstract}

Key words: Anacardium occidentale L., ensiling, sheep, nutritive value.

\section{INTRODUÇÃO}

Dentre as possibilidades de conservação de volumosos, o capim-elefante na forma de silagem tem se destacado. No Estado de Minas Gerais (FAEMG, 2006), mais de $40 \%$ das propriedades leiteiras utilizam

\footnotetext{
IDepartamento de Zootecnia, Universidade Federal do Rio Grande do Norte (UFRN), Natal, RN, Brasil.

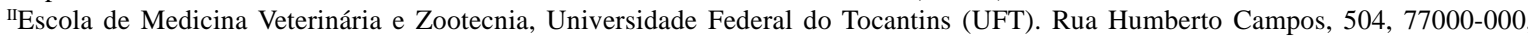
Araguaína, TO, Brasil. E-mail: araguaia2007@gmail.com. Autor para correspondência.

IIIDepartamento de Zootecnia, Universidade Federal Rural de Pernambuco (UFRPE), Recife, PE, Brasil.

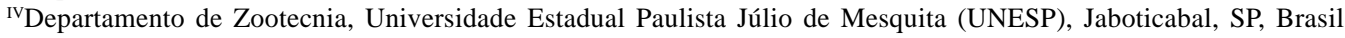

vDepartamento de Zootecnia, Universidade Federal do Ceará (UFC), Fortaleza, CE, Brasil.

VIDepartamento de Produção Animal, Universidade Federal de Goiás (UFG), Goiânia, GO, Brasil.
} 
esse volumoso. No entanto, vários autores têm chamado a atenção para as limitações da ensilagem do capim-elefante devido, principalmente, ao elevado teor de umidade (FERREIRA et al., 2004; CÂNDIDO et al., 2007; VIEIRA et al., 2007; FERREIRA et al., 2007, GONÇALVES et al., 2007; FERREIRA et al., 2007, COAN et al., 2009, RIBEIRO et al., 2009). Todos os autores, assumindo a existência dessa limitação, avaliaram a adição de subprodutos agroindustriais visando a melhorar o processo fermentativo e consequentemente o valor nutritivo das silagens. Assim, vários aditivos têm sido testados com a finalidade de melhorar o processo fermentativo e a qualidade da silagem do capim-elefante.

O cajueiro (Anacardium occidentale L.) é uma planta tropical originária do Brasil que se adapta bem em quase todo o seu território (SILVA, 1993). A região Nordeste, com uma área plantada superior a 650 mil hectares e produção de 160 mil toneladas de castanha, responde por mais de $95 \%$ da produção nacional, sendo os Estados do Ceará, do Piauí, do Rio Grande do Norte e da Bahia os principais produtores (IBGE, 2006). Segundo HOLANDA et al. (1996), a castanha representa $10 \%$ do peso do caju, e o pedúnculo representa $90 \%$, podendo se estimar que a produção anual de pedúnculo seja de 1,6 milhão de toneladas.

Com a instalação de agroindústrias no Nordeste brasileiro, diversos subprodutos vêm sendo disponibilizados e avaliados a fim de serem utilizados como alimentos alternativos na pecuária da região, podendo reduzir custos na produção animal. Dentre as culturas com produção significativa de subprodutos, destaca-se o caju; sendo assim, o presente trabalho foi desenvolvido com o objetivo de avaliar o valor nutritivo de silagens de capim-elefante com diferentes níveis de adição do pseudofruto (pedúnculo) do caju desidratado.

\section{MATERIAL E MÉTODOS}

Foram estudados cinco níveis de adição do pedúnculo de caju (Anacardium occidentale L.) desidratado (PCD) $(0 ; 4 ; 8 ; 12$ e 16\%), com base na matéria natural e na ensilagem do capim-elefante (Pennisetum purpureum, Schum.).

Na confecção das silagens experimentais, foi utilizado o capim-elefante proveniente de capineira estabelecida na Fazenda Experimental Vale do Curu em Pentecoste, Ceará (CE). O capim foi cortado manualmente com, aproximadamente, 70 dias de idade e, em seguida, foi processado em picadeira de forragem e, posteriormente, misturado ao PCD.
Na colheita das castanhas de caju, o pedúnculo é descartado, e foi esse o material que, após recolhido no campo, passou por processo de desidratação até atingir o nível de umidade em torno de $15 \%$. O pedúnculo de caju foi obtido na empresa CIONE (Companhia de Óleos Nordeste), em Fortaleza$\mathrm{CE}$, sendo a desidratação feita em estufa de circulação forçada de ar a $45^{\circ} \mathrm{C}$. Após desidratação, o PCD foi triturado em moinho com peneira de $1,0 \mathrm{~cm}$ de diâmetro.

No momento da ensilagem, o capim-elefante apresentava 16,80\% de matéria seca (MS), 88,05\% de matéria orgânica (MO), 5,58\% de proteína bruta (PB), $76,57 \%$ de fibra em detergente neutro (FDN), 47,62\% de fibra em detergente ácido (FDA), 28,95\% de hemicelulose, 4,30\% de extrato etéreo (EE), 78,17\% de carboidratos totais (CHT), 1,60\% de carboidratos não fibrosos (CNF), 63,81\% de nitrogênio insolúvel em detergente neutro (NIDN, \% do $\mathrm{N}$ total) e $20,65 \%$ de nitrogênio insolúvel em detergente ácido (NIDA, \% do $\mathrm{N}$ total). O PCD apresentava 86,02\% de MS, 94,80\% de MO, 8,67\% de PB, 31,53\% de FDN, 26,48\% de FDA, 5,05\% de hemicelulose, 5,29\% de EE, 80,84\% de CHT, 49,31\% de CNF, 64,19\% de NIDN (\% do N total) e 51,05\% de NIDA (\% do $\mathrm{N}$ total), com base na MS.

Como silos experimentais, foram utilizados tambores plásticos de 210L. Após a pesagem e homogeneização do capim-elefante com o PCD, o material foi compactado no interior do silo. Em cada silo, foram colocados $126 \mathrm{~kg}$ de forragem, a qual foi compactada por homens até atingir densidade de $600 \mathrm{~kg}$ $\mathrm{m}^{-3}$. Os silos foram fechados com lonas plásticas presas com ligas de borracha.

Para avaliação da digestibilidade das silagens, foram utilizados 20 carneiros machos, sem raça definida, com peso vivo médio inicial de $18,20 \mathrm{~kg}$. O delineamento adotado foi o inteiramente casualizado, com cinco tratamentos $(0,4,8,12$ e $16 \%$ de adição de PCD) e quatro repetições, sendo o animal considerado a unidade experimental. Para cada animal, foi utilizada a silagem oriunda de único silo experimental. Os animais foram pesados no início e ao final do experimento.

Os ovinos foram alojados em gaiolas de metabolismo, com cochos, para fornecimento de água, mistura mineral e dietas experimentais. O experimento teve duração de 17 dias, sendo 12 dias para adaptação dos animais às dietas e ao ambiente experimental e cinco dias para a coleta de amostras. As silagens foram fornecidas diariamente ad libitum em dois períodos, manhã e tarde, sendo a quantidade oferecida calculada diariamente, a partir do consumo do dia anterior, de modo que permitisse sobras de aproximadamente $15 \%$. Foram tomadas amostras compostas dos alimentos, sobras e fezes, que foram conservadas a $-10^{\circ} \mathrm{C}$ para 
análises posteriores. A urina foi medida pela manhã, ocasião na qual uma alíquota de $10 \%$ do total era coletada, acondicionada em frascos e conservada a $10^{\circ} \mathrm{C}$ para posteriores análises.

Nas amostras de alimento, sobras e fezes, foram determinados os teores de MS, MO, PB, FDN, FDA e EE segundo metodologia descrita por SILVA \& QUEIROZ (2002). Os valores de CHT foram obtidos por diferença, de acordo com a metodologia descrita por SNIFFEN et al. (1992), e os teores de CNF foram calculados pela diferença entre CHT e FDN, segundo HALL (2001). Na tabela 1 é apresentada a composição bromatológica das silagens estudadas.

Foram avaliados os consumos de MS, MO, PB, FDN, FDA, EE, CHT, CNF e NDT e as digestibilidades da MS, MO, PB, FDN, FDA, EE, CHT e CNF, bem como o balanço de nitrogênio das silagens (SILVA \& LEÃO, 1979) e o teor de NDT, segundo SNIFFEN et al. (1992).

Os dados obtidos foram inicialmente analisados quanto ao atendimento das pressuposições de normalidade, aditividade e homocedasticidade. Os dados obtidos para consumo de PB (\% PV, $\left.\mathrm{g} \mathrm{kg}^{-1} \mathrm{PV}^{0,75}\right)$, CHT (\% PV, g kg-1 $\mathrm{PV}^{0,75}$ ) e NDT(\%) foram transformados para $\log _{10}$, enquanto os de balanço de nitrogênio (BN) foram transformados em $(\mathrm{BN}+1)$ para se proceder à análise de regressão.

Foi efetuada análise de variância e de regressão nos dados relativos ao consumo e à digestibilidade de nutrientes e ao balanço de nitrogênio. A escolha dos modelos baseou-se na significância dos coeficientes linear e quadrático, por meio do teste t de “Student”, aos níveis de 1 e $5 \%$ de probabilidade. Como ferramenta de auxílio às análises estatísticas, foi adotado o procedimento PROC REG do Software SAS (2001).

\section{RESULTADOS E DISCUSSÃO}

A adição de PCD na ensilagem de capimelefante não influenciou ( $\mathrm{P}>0,05)$ o CMS e CMO expresso em \% PV e g kg-1 $\mathrm{PV}^{0,75}$ (Tabela 2). Esperavase que, com adição de PCD, houvesse elevação nos consumos de MS e MO, pois há tendência que isso ocorra quando o teor de MS das silagens eleva, e os teores de FDN decrescem (VAN SOEST (1994), EVANGELISTAet al. (2000), GONÇALVES et al. (2006), NEIVA et al. (2006), COAN et al. (2007), TAVARES et al.(2009) e RIBEIRO et al. (2009)). No presente estudo, os teores de MS das silagens aumentaram de 17,96\%, no nível $0 \%$, para 23,72\%, no nível $16 \%$ de PCD, enquanto o teor de FDN reduziu de $72,66 \%$, no nível 0\%, para 61,30\%, no nível 16\% de PCD. É possível que a elevação nos teores de NIDA (51,05\%), expressos como percentagem do $\mathrm{N}$ total (Tabela 1 ), tenha limitado o consumo de MS devido à baixa disponibilidade de nitrogênio para a atividade microbiana ruminal. Essa pressuposição pode ser confirmada pelos dados obtidos por NEIVA et al. (2006), que observaram elevação nos consumos de MS de silagens de capimelefante contendo níveis semelhantes de subproduto de maracujá desidratado e teores de MS variando de 15,1 a 24,3\%, porém com níveis de NIDA inferiores a $17 \%$.

É importante ressaltar, entretanto, que os consumos de MS, embora não tenham se alterado, foram relativamente bons (46,38g $\mathrm{kg}^{-1} \mathrm{PV}^{0,75}$ ) em se tratando de silagens de capim-elefante, pois estão ligeiramente superiores aos estabelecidos pelo ARC (1980), que é de $42 \mathrm{~g} \mathrm{~kg}^{-1} \mathrm{PV}^{0,75}$.

Tabela 1 - Composição química das silagens de capim-elefante em função de níveis crescentes de pedúnculo de caju desidratado (PCD) na silagem de capim-elefante.

\begin{tabular}{|c|c|c|c|c|c|}
\hline \multirow{2}{*}{ Variáveis (\%) } & \multicolumn{5}{|c|}{------------------------Níveis de adição (\%) de PCD------------------------ } \\
\hline & 0 & 4 & 8 & 12 & 16 \\
\hline Matéria seca & 17,21 & 20,10 & 21,18 & 22,65 & 23,20 \\
\hline Matéria orgânica & 88,60 & 88,13 & 89,60 & 89,91 & 89,92 \\
\hline Proteína bruta & 5,88 & 6,95 & 7,15 & 7,71 & 7,97 \\
\hline Fibra em detergente neutro & 73,92 & 69,04 & 65,99 & 63,51 & 62,54 \\
\hline Fibra em detergente ácido & 48,54 & 42,07 & 42,95 & 39,98 & 39,42 \\
\hline Hemicelulose & 25,38 & 26,96 & 23,04 & 23,52 & 23,12 \\
\hline Extrato etéreo & 2,34 & 2,58 & 2,76 & 3,41 & 4,63 \\
\hline Carboidratos totais & 78,39 & 78,60 & 79,70 & 78,79 & 77,32 \\
\hline Carboidratos não fibrosos & 4,46 & 9,56 & 13,70 & 15,28 & 14,78 \\
\hline Nitrogênio insolúvel em detergente neutro ${ }^{1}$ & 35,62 & 37,98 & 44,38 & 45,33 & 48,64 \\
\hline Nitrogênio insolúvel em detergente ácido ${ }^{1}$ & 18,26 & 18,02 & 24,72 & 27,17 & 29,63 \\
\hline
\end{tabular}

1-Porcentagem do nitrogênio total. 
Tabela 2 - Consumos de nutrientes em ovinos alimentados com silagens de capim-elefante, com níveis crescentes de adição de pedúnculo de caju desidratado (PCD).

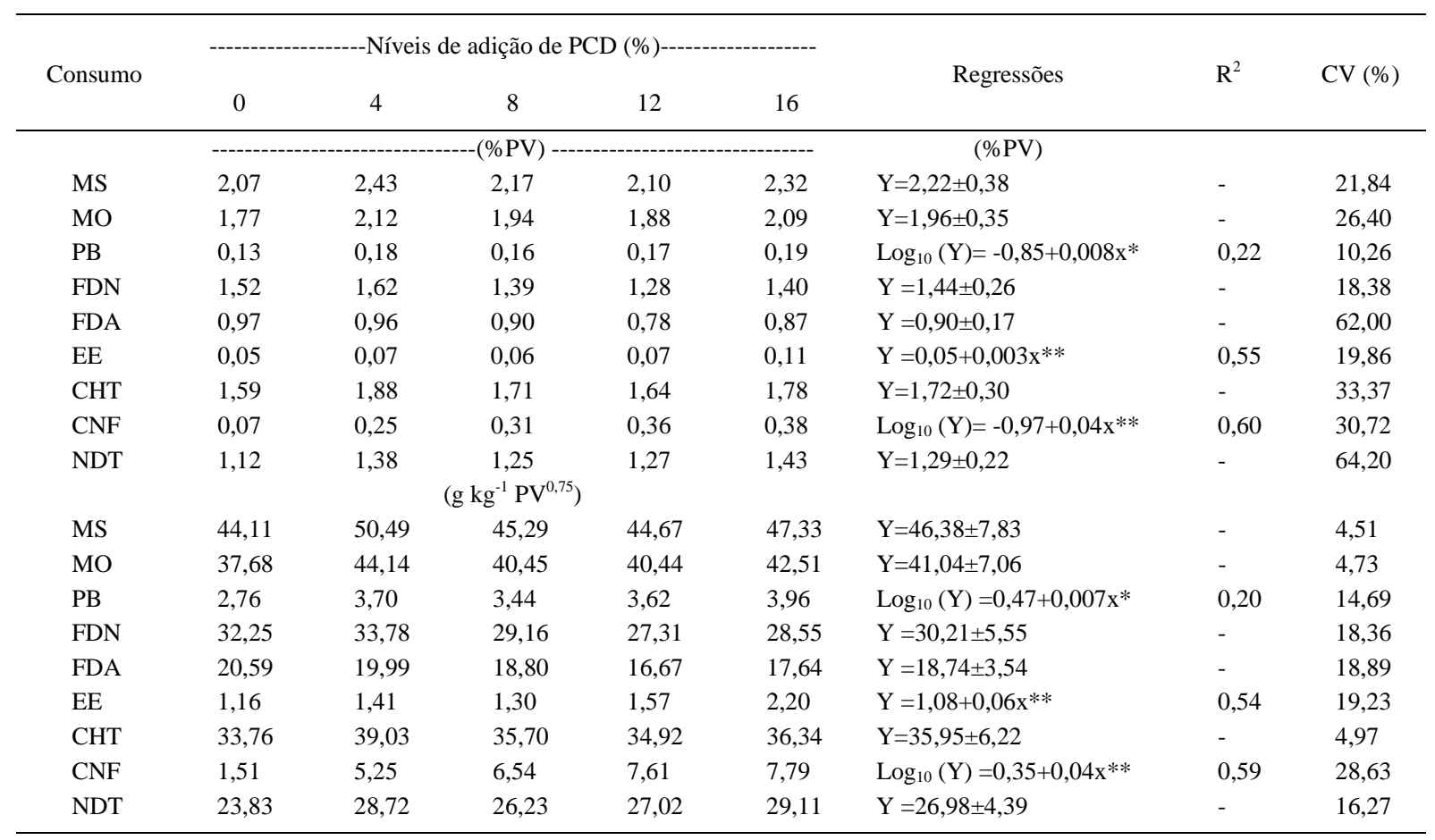

*5\% de probabilidade, **1\% de probabilidade.

MS - matéria seca, MO - matéria orgânica, PB - proteína bruta, FDN - fibra em detergente neutro, FDA - Fibra em detergente ácido, EE extrato etéreo, CHT - carboidratos totais, CNF - carboidratos não fibrosos e NDT - nutrientes digestíveis totais.

A adição do $\mathrm{PCD}$ aumentou $(\mathrm{P}<0,05)$ o consumo de PB em $0,003 \%$ do PV e $0,05 \mathrm{~g} \mathrm{~kg}^{-1} \mathrm{PV}^{0,75}$ para cada $1 \%$ de adição de PCD à silagem de capimelefante (Tabela 2). O incremento no consumo de PB pode estar relacionado ao aumento no teor de PB das silagens de capim-elefante com a inclusão de PCD. No entanto, o maior consumo de $\mathrm{PB}$ parece não ter surtido o efeito esperado, pois, conforme discutido anteriormente, o consumo de MS não foi alterado, provavelmente, devido à deficiência desse nutriente nas silagens. NEIVA et al. (2006) obtiveram aumento no consumo de $\mathrm{PB}$ de $0,20 \mathrm{~g} \mathrm{~kg}^{-1} \mathrm{PV}^{0,75}$ para cada $1 \%$ de inclusão de subproduto do processamento do maracujá na silagem de capim-elefante, valor superior ao obtido no presente estudo. Ocorre que, no estudo de NEIVA et al. (2006), além do aumento do teor de PB nas silagens, houve aumento no consumo de MS e isso permitiu que os animais atingissem maiores níveis ingestão.

$A$ adição de PCD às silagens de capimelefante não alterou $(\mathrm{P}>0,05)$ os consumos de FDN, FDA e CHT das silagens, expressos em \% PV e $\mathrm{g} \mathrm{kg}^{-1}$ $\mathrm{PV}^{0,75}$, em função da adição do PCD (Tabela 2).
Para os teores de CHT, os resultados obtidos são pertinentes, uma vez que o consumo de MS não foi influenciado pela a adição de PCD, e os teores desse componente nutricional também não tiveram seus teores alterados (Tabela 1). Já para os consumos de FDN e FDA, os dados obtidos são contraditórios, pois, embora o consumo de MS não tenha sofrido alteração, os teores desses componentes nutricionais decresceram significativamente com a adição do PCD às silagens (Tabela 1). É importante salientar que a média de consumo de FDN expressa em \% PV $(1,44 \%)$ é próxima do valor máximo (1,4\% PV) citado pelo NRC (2001) para bovinos de leite, porém 33\% abaixo do consumo obtido por DANTAS FILHO et al. (2007), que foi de 2,1\% PV, quando estudaram a inclusão de PCD em dietas balanceadas para ovinos em confinamento.

A adição do PCD aumentou o consumo de EE em $0,003 \%$ PV e $0,06 \mathrm{gg}^{-1} \mathrm{PV}^{0,75}$ para cada $1 \%$ de adição de PCD (Tabela 2). A elevação nos consumos de EE se deve à elevação dos teores desse nutriente nas silagens quando se adicionou o PCD, pois, enquanto na silagem exclusiva de capim-elefante o teor de EE foi de 2,34\%, nas silagens com 16\% de adição de PCD esse teor passou para 4,63\% (Tabela 1). 
A adição de PCD elevou $(P<0,01)$ os consumos de CNF das silagens (Tabela 2). Para cada $1 \%$ de adição de PCD às silagens, ocorreu elevação de $0,02 \%$ do PV e $0,46 \mathrm{~g} \mathrm{~kg}^{-1} \mathrm{PV}^{0,75}$ nos consumos de CNF. $\mathrm{O}$ acréscimo no consumo de CNF pode ser explicado pelo aumento do teor de CNF de 6,28\% nas silagens exclusivas de capim-elefante para $16,84 \%$ nas silagens contendo 16\% de PCD (Tabela 1).

$A$ adição de PCD às silagens de capimelefante não alterou $(\mathrm{P}>0,05)$ o consumo de NDT das silagens, expresso em \% PV e g kg-1 $\mathrm{PV}^{0,75}$. Como o consumo de MS não foi alterado pela adição de PCD (Tabela 2) e os valores de NDT aumentaram com a adição desse material, esperava-se que houvesse aumento no consumo de NDT. No entanto, é importante lembrar que os valores de NDT variaram de $54,06 \%$ nas silagens exclusivas de capim-elefante até 61,90 naquelas com o nível máximo de PCD. Como a amplitude da diferença foi de apenas 7,84 pontos percentuais e o coeficiente de variação foi de $16,27 \%$, não foi detectada significância. No entanto, esse efeito do maior teor de NDT pode ser observado principalmente por permitir melhor balanço de nitrogênio, conforme será visto a seguir.

As digestibilidades da MS, MO, PB, EE e CHT não foram alteradas $(\mathrm{P}>0,05)$ com a adição de $P C D$ às silagens (Tabela 3). Segundo VAN SOEST (1994), os constituintes da parede celular estão correlacionados negativamente com o consumo e a digestibilidade dos alimentos. No entanto, a redução dos teores de FDN e FDA das silagens com a adição do PCD não influenciou a digestibilidade da MS e da MO.
Apesar de o teor de CNF ter sido elevado com adição de PCD, as digestibilidades da MS e da MO não foram influenciadas, e outros fatores podem ter contribuído para tal resultado, como o elevado teor de NIDN e NIDA, que tornam indisponível o nitrogênio para os microrganismos do rúmen e limitam a ação destes sobre os componentes fibrosos (VAN SOEST, 1994).

As digestibilidades da MS e da MO das silagens de capim-elefante foram superiores às obtidas por MIZUBUTI et al. (2002), para silagem de milho (55,87\%) e sorgo (48,50\%), e por SOUZA et al. (2003), para silagem de sorgo (55,34\%), e à silagem de capimelefante, com adição de $14 \%$ de subproduto do processamento do maracujá (50,1\%) (NEIVA et al., 2006).

Já a baixa digestibilidade da PB das silagens com adição do $P C D$ pode estar relacionada ao elevado teor de NIDA do PCD. De acordo com VAN SOEST (1994), aumento nos teores de NIDA promove diminuição acentuada na digestibilidade da proteína, tornando o nitrogênio indisponível para os microrganismos do rúmen.

Não houve diferença na digestibilidade da FDN $(\mathrm{P}>0,05)$ entre as silagens com a inclusão de PCD, com média 58,97 $\pm 5,07 \%$. Resultados inferiores foram obtidos por NEIVA et al. (2006) para silagem de capimelefante com adição de subproduto do maracujá apresentando média de $47 \%$ de digestibilidade da FDN. No entanto, os valores obtidos no presente trabalho são próximos aos observados por FERREIRA et al. (2009), em que a digestibilidade aparente da fibra em

Tabela 3 - Valores médios para as digestibilidades aparentes, os nutrientes digestíveis totais e o balanço de nitrogênio em ovinos alimentados com silagens de capim-elefante, com níveis crescentes de adição de pedúnculo de caju desidratado (PCD).

\begin{tabular}{|c|c|c|c|c|c|c|c|c|}
\hline \multirow{2}{*}{ Variável } & \multicolumn{5}{|c|}{----------------Níveis de adição de PCD (\%)--------------- } & \multirow{2}{*}{ Regressões } & \multirow{2}{*}{$\mathrm{R}^{2}$} & \multirow{2}{*}{ CV $(\%)$} \\
\hline & 0 & 4 & 8 & 12 & 16 & & & \\
\hline DMS (\%) & 51,28 & 61,53 & 61,14 & 63,03 & 63,39 & $Y=61,67 \pm 4,05$ & - & 6,56 \\
\hline DMO (\%) & 60,71 & 63,74 & 63,47 & 65,74 & 65,28 & $Y=63,79 \pm 3,92$ & - & 6,15 \\
\hline DPB (\%) & 46,90 & 41,82 & 40,25 & 40,78 & 42,02 & $Y=42,35 \pm 6,71$ & - & 15,85 \\
\hline DEE (\%) & 61,11 & 60,81 & 57,51 & 57,69 & 57,70 & $Y=58,97 \pm 5,07$ & - & 8,60 \\
\hline DFDN (\%) & 61,11 & 60,81 & 57,51 & 57,69 & 57,70 & $Y=58,97 \pm 5,07$ & - & 8,60 \\
\hline DFDA (\%) & 56,96 & 50,37 & 50,96 & 47,41 & 46,83 & $Y=55,15-0,58 x^{*}$ & 0,27 & 10,35 \\
\hline DCHT(\%) & 62,57 & 66,67 & 66,41 & 68,86 & 67,67 & $Y=66,44 \pm 3,88$ & - & 5,85 \\
\hline DCNF (\%) & 89,25 & 100,00 & 100,00 & 100,00 & 100,00 & $Y=95,61+0,87 x^{*}$ & 0,25 & 7,86 \\
\hline NDT & 54,06 & 57,21 & 58,13 & 60,52 & 61,90 & $\log _{10}(Y)=1,74+0,003 x^{* *}$ & 0,38 & 1,39 \\
\hline BN (g/dia)) & $-0,11$ & 0,43 & 0,67 & 0,96 & 1,04 & $(\mathrm{BN}+1)(\mathrm{Y})=1,03+0,07 \mathrm{X}^{* *}$ & 0,33 & 34,72 \\
\hline
\end{tabular}

*5\% de probabilidade, $* * 1 \%$ de probabilidade.

$\mathrm{R}^{2}$ - Coeficiente de determinação, CV - coeficiente de variação, DMS - Digestibilidade da matéria seca (\%), DMO - Digestibilidade da matéria orgânica (\%), DPB - Digestibilidade da proteína bruta (\%), DFDN - Digestibilidade da fibra em detergente neutro (\%), DFDA Digestibilidade da fibra em detergente ácido (\%), DEE - Digestibilidade do extrato etéreo (\%), DCHT - Digestibilidade dos carboidratos totais (\%), DCNF - Digestibilidade dos carboidratos não fibrosos (\%), NDT -Nutrientes digestíveis totais (\%) e BN - Balanço de nitrogênio.

Ciência Rural, v.40, n.2, fev, 2010. 
detergente neutro não foi alterada em função da adição de subproduto do processamento do abacaxi, apresentando média de 55,2\%. Provavelmente as diferenças na qualidade do capim-elefante ensilado foram responsáveis pelo valor médio observado nos estudos citados anteriormente.

A inclusão de PCD na silagem de capimelefante promoveu efeito linear decrescente $(\mathrm{P}<0,01)$ na digestibilidade da FDA. Para cada $1 \%$ de adição de PCD, houve redução de 0,58 pontos percentuais na digestibilidade da FDA das silagens. É importante lembrar que, embora a adição de PCD diminua os teores de FDA, os teores de NIDA foram elevados nessas silagens. Dessa forma, a diminuição na digestibilidade da FDA é entendida e ainda ajuda a explicar o motivo pelo qual as digestibilidades da MS e MO não foram alteradas.

A adição do PCD à silagem de capim-elefante promoveu aumento na digestibilidade dos CNF de 0,87 pontos percentuais para cada $1 \%$ de inclusão de PCD, indicando que a adição do PCD melhorou a qualidade da silagem de capim-elefante. Os CNF são de fácil fermentação ruminal, o que permite maior aporte energético no rúmen (NRC, 2001), porém destaca-se que a fermentação ruminal desses nutrientes pode variar muito em função do tipo de alimento e do processamento.

Para os valores de nutrientes digestíveis totais (NDT), foi observado efeito linear crescente $(\mathrm{P}<0,01)$ com a inclusão do PCD. Para cada $1 \%$ de adição de PCD, ocorreu elevação de 0,40 pontos percentuais nos valores de NDT. O aumento nos valores de NDT com a adição de PCD às silagens se deve, principalmente, ao aumento nos teores de CNF (Tabela 1), que apresentou digestibilidade elevada nas silagens contendo PCD.

Verificou-se efeito linear crescente para balanço de nitrogênio (BN) das silagens, com aumento de $0,07 \mathrm{~g} \mathrm{dia}^{-1}$ no nitrogênio retido a cada $1 \%$ de adição do PCD. Esse comportamento é decorrente do incremento verificado para a ingestão de $\mathrm{PB}$ das silagens com PCD. A partir de 1\% de adição de PCD, o $\mathrm{BN}$ foi positivo, indicando que as silagens com PCD suprem as necessidades de ovinos em mantença e podem permitir algum ganho de peso.

Aumentos nos valores do BN em g/dia estão de acordo com os dados obtidos por vários autores, os quais, estudando a adição de subprodutos agroindustriais do processamento de frutas, observaram efeitos positivos sobre o BN (DANTAS FILHO et al., 2006; NEIVA et al., 2006; FERREIRAet al., 2009).

\section{CONCLUSÃO}

O pedúnculo de caju desidratado pode ser adicionado na ensilagem do capim-elefante até o nível de $16 \%$ da matéria natural, pois melhora o valor nutritivo das silagens. O nível de inclusão do pedúnculo de caju depende da disponibilidade e do custo operacional para obtenção desse subproduto.

\section{AGRADECIMENTOS}

Os autores agradecem o apoio financeiro da Coordenação de Aperfeiçoamento de Pessoal de Nível Superior (CAPES), do Conselho Nacional de Desenvolvimento Científico e Tecnológico (CNPq) e da FUNCAP, sem o qual a pesquisa não poderia ter sido realizada.

\section{REFERÊNCIAS}

AGRICULTURAL RESEARCH COUNCIL (ARC). The nutrient requirements of ruminant livestock. England: Agricultural Research. Council, Commonwealth Agricultural Bureaux, 1980. 351p.

CÂNDIDO, M.J.D. et al. Características fermentativas e composição química de silagens de capim-elefante contendo subproduto desidratado do maracujá. Revista Brasileira de Zootecnia, v.36, p.1489-1494, 2007. Disponível em: <http:/ /www.revistasbz.org.br/scripts/revista/sbz1/Artigos/6259.PDF > Acesso em 10 out. 2009. doi: 10.1590/S151635982007000700005 .

COAN, R.M. et al. Dinâmica fermentativa e microbiológica de silagens dos capins tanzânia e marandu acrescidas de polpa cítrica peletizada. Revista Brasileira Zootecnia, v.36, n.5, p.15021511, 2007 (supl). Disponível em: <http://www.revistasbz.org.br/ scripts/revista/sbz1/Artigos/5412.PDF>. Acesso em 10 out. 2009. doi: 10.1590/S1516-35982007000700007.

DANTAS FILHO, L.A. et al. Inclusão de polpa de caju desidratada na alimentação de ovinos: desempenho, digestibilidade e balanço de nitrogênio. Revista Brasileira de Zootecnia, v.36, n.1, p.147-154, 2007. Disponível em: <http://www.revistasbz.org.br/ scripts/revista/sbz1/Artigos/6075.PDF>. Acesso em 10 out. 2009. doi: 10.1590/S1516-35982007000100018.

EVANGELISTA, A.R. et al. Avaliação de algumas características da silagem de gramínea Estrela Roxa (Cynodon nlemfuensis Vanderyst). Revista Brasileira de Zootecnia, v.29, n.4, p.941-946, 2000. Disponível em: <http://www.revistasbz.org.br/ scripts/revista/sbz1/Artigos/2589.PDF>. Acesso em 10 out. 2009. doi: 10.1590/S1516-35982000000400001.

FAEMG - Federação da Agricultura do Estado de Minas Gerais. Diagnóstico da pecuária leiteira do Estado de Minas Gerais em 2005. Belo Horizonte: OCEMG-FAEMG-SEBRAESENAR, 2006. 158p.

Ciência Rural, v.40, n.2, fev, 2010. 
FERREIRA, A.C.H.. et al. Características químico bromatológicas e fermentativas do capim elefante ensilado com níveis crescentes de subproduto da agroindústria do abacaxi. Revista Ceres, v.54, p.98-106, 2007. Disponível em: <http:/ /www.ceres.ufv.br/CERES/revistas/V54N312P01607.pdf $>$. Acesso em 10 out. 2009.

FERREIRA, A.C.H.. et al. Valor nutritivo das silagens de capimelefante com diferentes níveis de subprodutos da indústria do suco de caju. Revista Brasileira de Zootecnia, v.33, n.6, p.13801385, 2004. Disponível em: <http://www.revistasbz.org.br/scripts/ revista/sbz1/Artigos/4136.PDF>. Acesso em 10 out. 2009. doi: 10.1590/S1516-35982007000700005.

FERREIRA, A.C.H. et al. Avaliação nutricional do subproduto da agroindústria de abacaxi como aditivo de silagem de capimelefante. Revista Brasileira de Zootecnia, v.39, n.2 p.223229, 2009. Disponível em: <http://www.revistasbz.org.br/scripts/ revista/sbz1/Artigos/7295.PDF>. Acesso em 10 out. 2009. doi: 10.1590/S1516-35982009000200002.

GONÇALVES, J.S. et al. Composição bromatológica e características fermentativas de silagens de capim-elefante (Pennisetum purpureum Schum.) cv. 'Roxo' contendo níveis crescentes do subproduto da semente do urucum (Bixa orellana L.). Revista Ciência Agronômica, v.37, n.2, p.228-234, 2006. Disponível em: http://ccarevista.ufc.br/seer/index.php/ ccarevista/article/viewFile/205/201. Acesso em 10 de out. 2009

GONÇALVES, J.S. et al. Valor nutritivo de silagens de capim elefante (Pennisetum purpureumShum) e Brachiaria decumbens contendo pedúnculo de caju (Annacardium occidentale L.) desidratado. Ciência Agronômica, v.38, n.2, p.204-209, 2007. Disponível em: <http://ccarevista.ufc.br/seer/index.php/ ccarevista/article/viewFile/139/134>. Acesso em 10 out. 2009.

HALL, M.B. Recent advanced in non-ndf carbohydrates for the nutrition of lactating cows. In: SIMPÓSIO INTERNACIONAL EM BOVINOS DE LEITE: Novos conceitos em nutrição, 2., 2001, Lavras. Anais... Lavras: Universidade Federal de Lavras, 2001. p.139-148.

HOLANDA, J.S. et al. Perspectiva de uso de pedúnculo de caju na alimentação animal. In: SIMPÓSIO NORDESTINO DE ALIMENTAÇÃO DE RUMINANTES, 6., 1996, Natal. Anais... Natal: SNPA, 1996. p.155-161.

INSTITUTO BRASILEIRO DE GEOGRAFIA E ESTATÍSTICAS: Acompanhamento sistemático da produção agrícola. Brasília: IBGE/SIDRA, 2006. 589p.

MIZUBUTI, I.Y. et al. Consumo e digestibilidade aparente das silagens de milho (Zea mays L.), sorgo (Sorghum bicolor (L.) Moench) e girassol (Helianthus annuus L.). Revista Brasileira de Zootecnia, v.31, n.1, p.267-272, 2002. Disponível em: <http://www.revistasbz.org.br/scripts/revista/sbz1/Artigos/ 3246.PDF>. Acesso em 10 out. 2009. doi: 10.1590/S151635982002000100029 .
NATIONAL RESEARCH COUNCIL - NRC. Nutrient requiriments of dairy cattle. 7.ed. Washington D.C., 2001. 381p.

NEIVA, J.N.M. et al. Valor nutritivo de silagens de capim-elefante enriquecidas com subproduto do processamento do maracujá. Revista Brasileira de Zootecnia, v.35, n.4, p.1843-1849, 2006. Disponível em:<http://www.revistasbz.org.br/scripts/ revista/sbz1/Artigos/5280.PDF>. Acesso em 10 out. 2009. doi:10.1590/S1516-35982006000600036.

RIBEIRO, J.L. et al. Efeitos de absorventes de umidade e de aditivos químicos e microbianos sobre ovalor nutritivo, o perfil fermentativo e as perdas em silagens de capim-marandu. Revista Brasileira de Zootecnia, v.38, n.2, p.230-239, 2009. Disponível em: <http://www.revistasbz.org.br/scripts/revista/ sbz1/Artigos/7155.PDF>. Acesso em 10 out. 2009. doi: 10.1590/S1516-35982009000200003

SILVA, D.J.; QUEIROZ, A.C. Análises de alimentos: Métodos químicos e biológicos. 2.ed. Viçosa: UFV, 2002. 165p.

SILVA, J.F.C.; LEÃO, M.I. Fundamentos de nutrição dos ruminantes. Piracicaba: Livroceres, 1979. p.190-236.

SILVA, V.A. Aspectos agroeconômicos sobre a cultura do cajueiro. Fortaleza: EMBRAPA-CNPAT, 1993. 124p.

SNIFFEN, C.J. et al. A net carbohydrate and protein system for evaluating cattle diets: II. Carbohydrate and protein availability. Journal of Animal Science, v.70, n.11, p.3562-3577, 1992.

SOUZA, V.G. et al. Valor nutritivo de silagens de sorgo. Revista Brasileira de Zootecnia, v.32, n.3, p.753-759, 2003. Disponível em: http://www.revistasbz.org.br/scripts/revista/sbz1/ Artigos/3653.PDF. Acesso em 10 out. 2009. doi: 10.1590/ S1516-35982003000300028

STATISTICAL ANALYSES SYSTEM - SAS. User's guide. Cary, NC: SAS Institute, 2001. 397p.

TAVARES, V.B. et al. Efeitos da compactação, da inclusão de aditivo absorvente e do emurchecimento na composição bromatológica de silagens de capim-tanzânia. Revista Brasileira de Zootecnia, v.38, n.1, p.40-49, 2009. Disponível em: <http://www.revistasbz.org.br/scripts/revista/sbz1/Artigos/ 7220.PDF $>$. Acesso em 10 out. 2009. doi: 10.1590/S151635982009000100006.

VAN SOEST, P.J. Nutritional ecology of the ruminant. 2.ed. Ithaca, New York: Cornell University, 1994. 476p.

VASCONCELOS, V.R. et al. Utilização de subprodutos da indústria frutífera na alimentação de caprinos e ovinos. Sobral:EMBRAPA-Caprinos/CE, 2002. 36p. (EMBRAPACaprinos. Documentos, 42).

VIEIRA, M.M.M. et al. Valor nutritivo de silagens de capim elefante contendo níveis de farelo de babaçu. Archivos de Zootecnia, v.56, p.257-260, 2007. Disponível em: $<$ http:// www.uco.es/organiza/servicios/publica/az/php/img/web/ 04_21_03_17NotaValorVieira.pdf>. Acesso em 10 out. 2009. 